\title{
Infiltração de água em uma mina subterrânea de ouro: Um modelo geoelétrico na otimização ao bombeamento de galerias subterrâneas
}

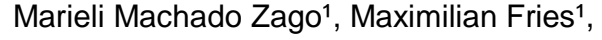 \\ Laboratório de Geofísica Aplicada, Universidade Federal do Pampa (UNIPAMPA).
}

Copyright 2018, SBGf - Sociedade Brasileira de Geofísica

Este texto foi preparado para a apresentação no VIII Simpósio Brasileiro de Geofísica, Salinópolis, 18 a 20 de setembro de 2018. Seu conteúdo foi revisado pelo Comitê Técnico do VIII SimBGf mas não necessariamente representa a opinião da SBGf ou de ourcial deste material para propósitos comerciais sem prévia autorização da SBGf.

\section{Resumo}

Os recursos minerais são fundamentais para a existência da humanidade e sua exploração é sinônimo de progresso e avanço. O século XXI é caracterizado pela preservação aos recursos hídricos da Terra. $O$ cuidado e reutilização de forma sustentável é um dos principais objetivos dos orgãos públicos e da população nos dias de hoje. A mineração geralmente ocorre através da abertura de minas subterrâneas ou cavas a céu aberto, algumas das quais, desenvolvidas abaixo do lençol freático, causando intensa infiltração de água na subsuperfície e percolação. Nos casos em que o volume de água é relativamente grande, há perdas financeiras e atrasos nos processos de exploração. Considerando isto, investigações geológicas e estruturais subsuperficiais com o objetivo de caracterizar as áreas da zona de recarga, principais rotas e concentração para a solução onipresente de infiltração de água são necessários. O presente estudo sugere o uso do método geofísico da eletrorresistividade em uma área de mina subterrânea em pleno funcionamento no município de Faina, Estado de Goiás, Brasil. Um total de 12 perfis (caminhamento elétrico) foram adquiridos e sua interpretação e análise possibilitaram a geração de um modelo de visualização tridimensional com as variações de resistividade no local (modelo geoelétrico) integrado com a localização das galerias subterrâneas. Os resultados mostraram contrastes significativos de resistividade (baixos resistivos anômalos) associados aos fluxos de água, zona de recarga, acúmulo de água e estruturas de subsuperfície relacionadas. O estudo representou uma abordagem eficaz e serviu como auxílio no planejamento de locação e determinação da quantidade das bombas (estimativa de vazão) contribuindo na otimização do processo de drenagem. Fornece, também, subsídios importantes a futuros estudos como um modelo hidrogeológico mais abrangente na área.

\section{Introdução e Objetivos}

A água é um elemento vital para a vida humana e sua escassez não é apenas física, mas também pode ser econômica, no sentido de não haver recursos (Lopes, 2009). É importante também para o funcionamento de processos e operações em atividades de mineração. Considerando que algumas minas se desenvolvem abaixo do nível freático e há incidência, além das águas superficiais e meteóricas, da flutuação do nível freático com menor ou maior intensidade causando infiltrações. Em alguns casos ocorre grande vazão em galerias subterrâneas e cavas acarretando, consequentemente, prejuízos e atrasos nos processos de explotação dos recursos minerais (Rubio, 2006).

Em diversas minas espalhadas ao redor do mundo ocorre a extração de grande quantidade de água. Esse é o caso de minas localizadas abaixo do nível piezométrico, e de aquíferos livres e confinados, dos quais deve ser bombeada enquanto durar a explotação da mina. Neste caso é necessário a implementação de ações para reduzir a percolação da água à lavra com medidas como o desvio do escoamento superficial, o aproveitamento de barreiras geológicas, a prevenção do fraturamento de tetos e trabalhos de impermeabilização. No caso destas medidas de prevenção não solucionar a problemática, pode-se efetuar a drenagem da mina. Uma tecnologia muito conveniente é a denominada Drenagem Preventiva em Avanço (DPA) (Rubio, 2006).

A técnica DPA consiste em extrair a água do aquífero em setores afastados da lavra, de maneira que a água não seja afetada pelas operações da mina, dessa forma é possível reduzir o nível piezométrico abaixo das cotas da frente de lavra, podendo obter-se água para atender as demandas das operações de mineração e a de abastecimentos de quaisquer tipos. A DPA é aplicada em diversos tipos de mineração, como, por exemplo, em minas de zinco, carvão-bauxita e ouro (Rubio, 2006).

A geofísica representa uma eficiente abordagem para o auxílio na identificação de contatos, estruturas geológicas e na diferenciação das camadas litológicas em subsuperfície, a partir do contraste de propriedades físicas encontradas em rochas, minerais e fluídos percolantes. Estudos anteriores como Filho (1997), Elis et al. (2004), Oliveira (2011), Oliva et al. (2006), Nazaruddin et al. (2017) apresentaram resultados satisfatórios na identificação de anomalias em seções de eletrorresistividade correlacionadas com a presença de zonas saturadas em subsuperfície.

A proposta deste trabalho foi de utilizar o método da eletrorresistividade em uma mina subterrânea de ouro com abundante infiltração de água nas galerias subterrâneas por meio de estruturas geológicas (falhas e fraturas). O principal objetivo foi detectar os contrastes de resistividade em subsuperfície a fim de determinar-se o contato e a localização entre a zona insaturada e saturada (nível d'água). Com a definição destes limites e profundidades, a instalação das bombas pode ser otimizada levando-se a uma considerável redução de custo e tempo no processo.

A área de estudo situa-se a $8 \mathrm{~km}$ da zona urbana do município de Faina e aproximadamente $250 \mathrm{~km}$ da capital 
Goiânia, estado de Goiás, Brasil. O principal acesso se dá pela rodovia GO-164. No local encontra-se as instalações da Mineração Curral de Pedra Ltda. sendo a principal atividade a extração de ouro em galerias subterrâneas na mina denominada de Cascavel (Figura 1a e b).

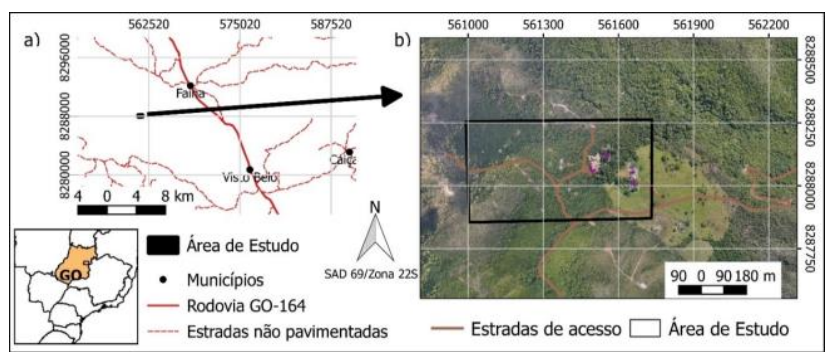

Figura 1 - Área de estudo com municípios e rodovia GO$164 \mathrm{em}$ a). Detalhe da área e principais estradas de acesso b). Adaptado de SIEG, 2017 e Orinoco Gold, 2017.

\section{Contexto geológico}

Regionalmente insere-se na Província Estrutural Tocantins desenvolvida durante o Ciclo Brasiliano que ocorreu no Neoproterozoico (Almeida et al., 1977), sendo, o Maciço de Goiás, principal representante da província, situado na região centro-oeste de Goiás e na porção central da Província de Tocantins. É formado por segmentos colisionais brasilianos que envolvem um microcontinente arqueano (Fuck, 1994). O maciço é composto por Complexos Granito-gnáissicos, correspondente a $80 \%$ da área total, e por Greenstone Belts com $20 \%$ da área (Jost et al., 2005).

Localmente encontra-se lentes de rochas ultramáficas, metarritmitos, quartzito feldspático, metapelitos e um material argiloso ferruginisado com alto teor em cobre $(\mathrm{Cu})$, prata $(\mathrm{Ag})$ e tungstênio $(\mathrm{W})$. Em até 200 metros de profundidade observa-se lama e rocha carbonática impura com fraturamento moderado. (Orinoco Gold, 2017). As galerias subterrâneas da mina estão localizadas entre metarritmitos e quartzitos feldspático. No entorno das galerias encontra-se quartzito feldspático com espessura variando de 80 a 120 metros. Há predomínio de foliações e lineações fortemente penetrativas (Orinoco Gold, 2017) (Figura 2).

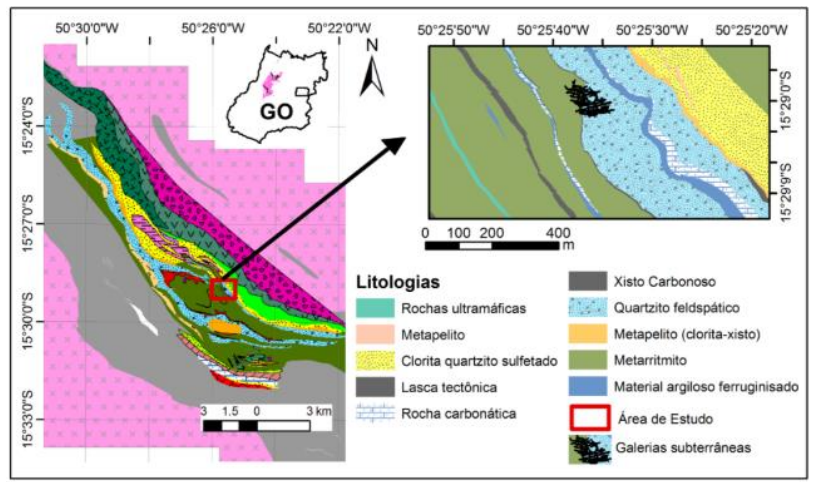

Figura 2 - Composição de mapas com o Greenstone Belt Faina e detalhe das litologias da área de estudo (retângulo vermelho) onde se localizam as galerias subterrâneas da mina Cascavel. Adaptado de Orinoco Gold, 2017.

A mina Cascavel possui três principais faces de desenvolvimento nas galerias subterrâneas, a água nessas faces, migra constantemente de uma para a outra. Uma dessas faces sempre apresenta um volume maior de água, alternando conforme o aprofundamento das três galerias (Mineração Curral de Pedra, 2017) (Figura 3).

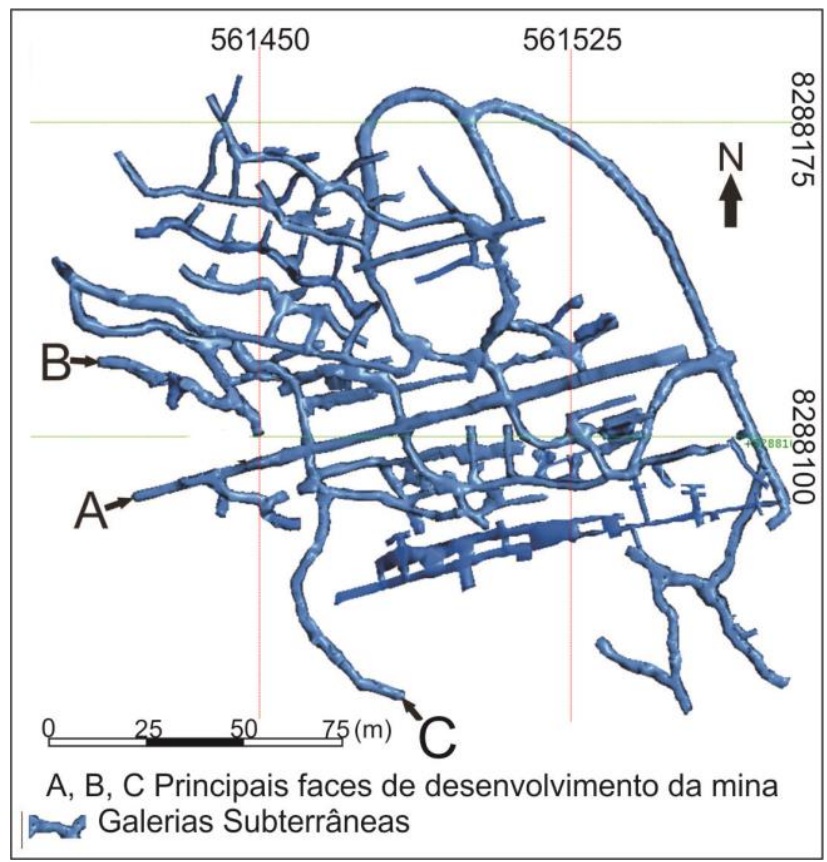

Figura 3 - Galerias subterrâneas da mina Cascavel e indicação da localização da percolação de água nas faces de desenvolvimento ( $A, B$ e $C$ ). Adaptado de Mineração Curral de Pedra, 2017.

Com o avanço das galerias ocorre a redução ou o aumento do volume de água. Na Figura $4 \mathrm{a}$ observa-se infiltração de água pelas cavilhas do teto da galeria e por fraturas no desenvolvimento do plano inclinado. Na Figura 4b observa-se água acumulada que flui por meio de fraturas e na Figura 4c nota-se um pequeno volume de água no piso, proveniente de fraturas na rampa de acesso das galerias.

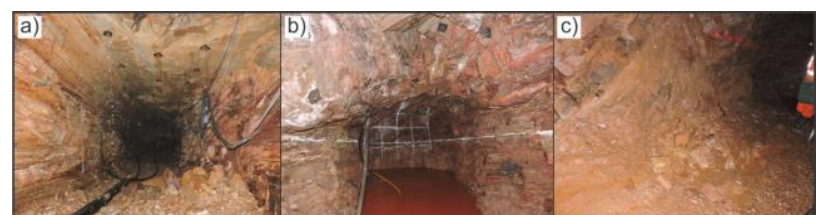

Figura 4 - Fotos da água nas faces de desenvolvimento $A$, $B$ e C. Em a) localizada no plano inclinado, b) grande quantidade de água na galeria e c) água na rampa de acesso das galerias. Adaptado de Mineração Curral de Pedra, 2017.

Um dos principais meios de percolação de água é a presença de stockworks de quartzo com manganês (Figura 5). A baixa porosidade dos veios sela a água nos 
blocos gerados entre os stockworks e a água migra ao longo dos planos desses veios e entre os planos de foliação da rocha.

A mina encontra-se em pleno funcionamento devido ao auxílio de bombas que realizam constantemente a drenagem da água para a superfície. São duas bombas operando com uma taxa de vazão de $75 \mathrm{~m}^{3} / \mathrm{h}$ cada (Orinoco Gold, 2017).

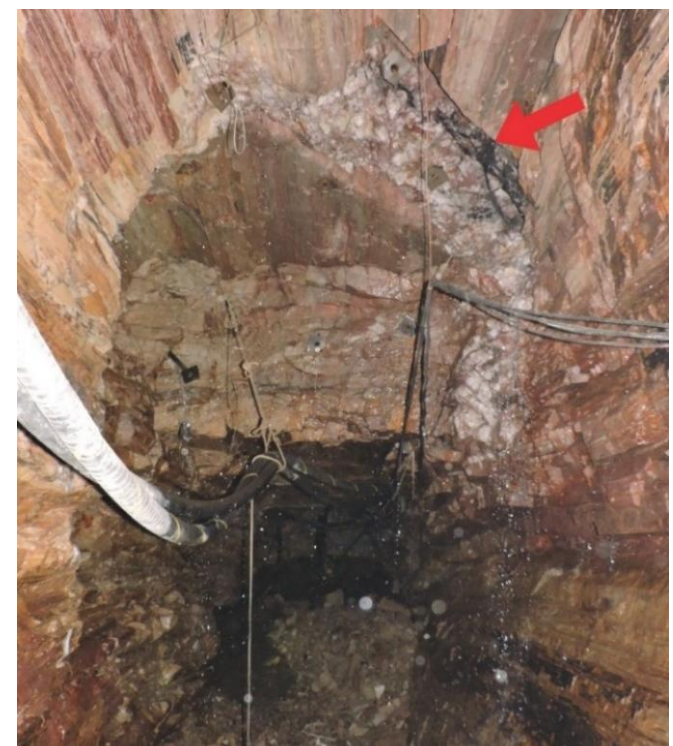

Figura 5 - Veios de quartzo com óxido de manganês (seta vermelha) no entorno das galerias subterrâneas. Extraído de Mineração Curral de Pedra, 2017.

\section{Metodologia}

Para a execução deste estudo foram desenvolvidas as etapas, conforme apresentado na Figura 6.

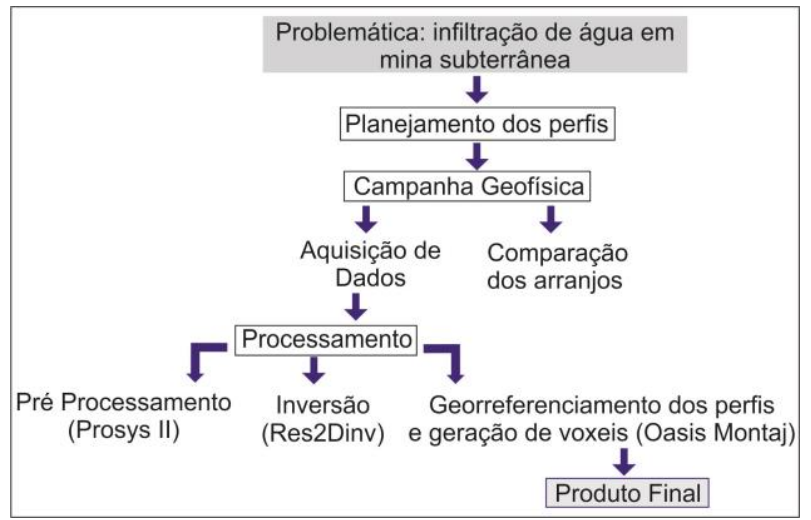

Figura 6 - Fluxo de atividades das etapas de desenvolvimento deste estudo.

A Mina Cascavel localiza-se sobre uma área de relevo acentuado, vegetação densa e ocorrência de estruturas geológicas (falhas e fraturas) que facilitam a percolação de água para as galerias da mina (Figura 7).

Determinou-se que os perfis de Caminhamento Elétrico fossem realizados seccionando as principais estruturas, a fim de melhor caracterizar, por meio de contrastes de resistividade elétrica dos materiais, os contatos entre as litologias e estruturas.

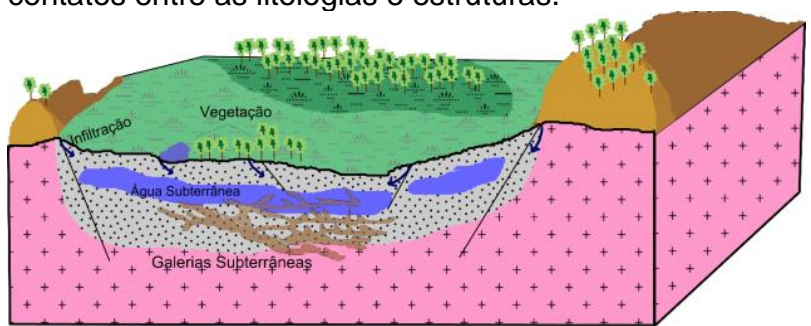

Figura 7 - Esquema simplificado com as principais características no entorno da mina Cascavel.

O equipamento usado foi um resistivímetro modelo Syscal Pro, fabricado pela Iris Instruments, de propriedade da Universidade Federal do Pampa Unipampa, Campus Caçapava do Sul.

Foram realizados um total de 12 perfis de direção S218W com extensão de 360 metros e 5 metros de espaçamento entre eletrodos. Considerou-se um espaçamento de 10 e 20 metros entre os perfis, visando uma cobertura densa de dados.

A geometria de arranjo utilizada foi a Polo Dipolo, programado com 7 níveis de investigação, atingindo assim, aproximadamente 80 metros de profundidade.

De acordo com Loke (2000) no arranjo polo dipolo é preciso que um eletrodo remoto seja disposto a uma distância suficientemente longe do perfil de levantamento, para isso, utilizou-se 500 metros de fio elétrico, conectado ao resistivímetro Syscal Pro localizado na região central do arranjo (Figura 8).

$\begin{array}{ll}\text { - Multicabos de } 90 \text { metros } & \text { Resistivimetro Syscal Pro } \\ \text { - Caixas de conexão } & \text { Fio elétrico de } 500 \text { metros } \\ \text { - Bateria } 12 \text { Volts } & \end{array}$

Figura 8 - Esquema representando o desenvolvimento do arranjo polo dipolo em campo.

Para interpretação e análise os perfis de eletrorresistividade foram classificados em: i) Perfis ER Zona de Recarga; ii) Perfis ER - Galeria Mestre e iii) Perfis ER - Área Sul. Cada perfil possui uma identificação com uma numeração seguido de uma letra (Figura 9).

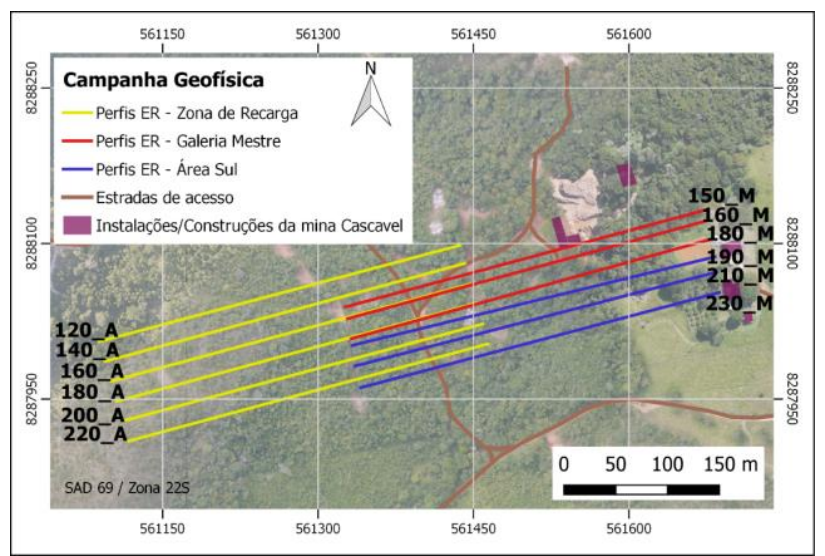

Figura 9 - Localização dos perfis de eletrorresistividade na área de estudo. 


\section{Processamento dos dados}

Foi utilizado o software Prosys II (Fabricado pela Iris Instruments) para transferência (equipamento computador) de dados. O pré-processamento consistiu nas fases; i) inserção da topografia do perfil, ii) controle dos valores de resistividade inicial com a remoção de valores negativos, iii) seleção de uma faixa (range) de valores de resistividade inicial e iv) controle do desvio padrão dos valores.

A partir deste procedimento foi gerado um arquivo e importado para o software res2Dinv para realização do processo de inversão dos valores de resistividade elétrica aparente medida. Para definição da quantidade de iterações que seriam utilizados para todos os perfis foram executados testes e observou-se que entre a $4^{\circ}$ e $5^{\circ}$ iteração ocorreu menor variação no percentual de erro RMS. Desta forma definiu-se 5 iterações para todas as seções de eletrorresistividade.

Como etapa final foi efetuado o georreferenciamento dos valores de resistividade elétrica dos perfis com o uso do software Oasis Montaj da Geosoft. A geração de células com os valores interpolados (voxels) que representa um valor em uma malha (grid) regular em um espaço tridimensional. $O$ número de células $X / Y / Z$ foi de $29 / 110 / 92$, e considerou-se a quantidade de 2 pixels para a geração de células. Apenas os valores de resistividade elétrica entre 0 e $200 \mathrm{ohm}$.m foram selecionados para a visualização tridimensional das células. Os demais valores foram desconsiderados a fim de otimizar o resultado final (objetivo do trabalho).

\section{Resultados e discussões}

Foi gerado inicialmente um mapa topográfico juntamente com a representação das galerias subterrâneas (com 60 \% de transparência na malha de dados topográficos) (Figura 10).

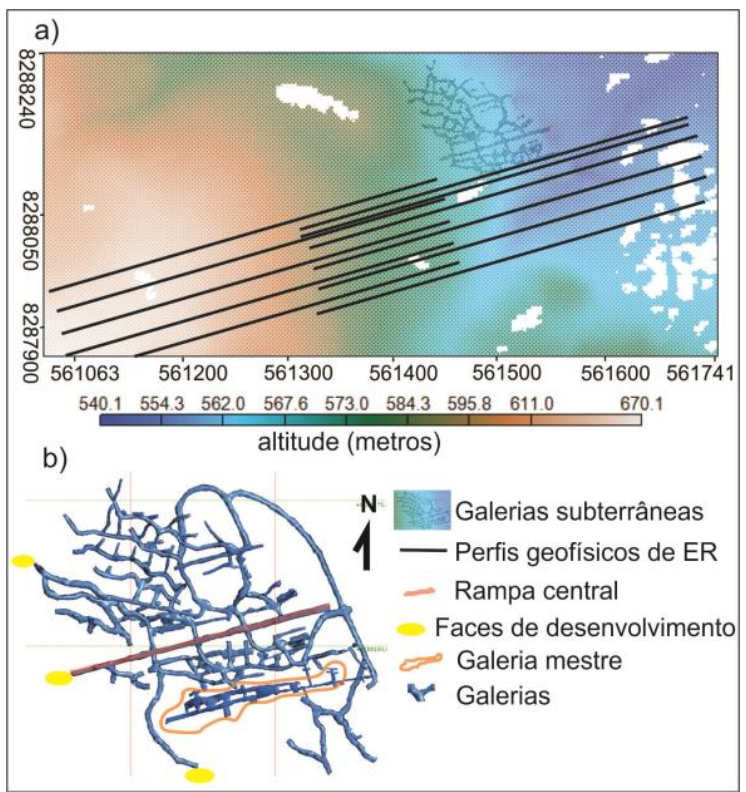

Figura 10 - a) Mapa de variação dos valores altimétricos na área, localização dos perfis de eletroressistividade e galerias da Mina Cascavel. Em b) localização das galerias subterrâneas com identificações de pontos importantes.

Pode-se observar na Figura 10a a integração com a localização dos perfis de eletrorresistividade em superfície.

A identificação das três faces de desenvolvimento (principais locais das galerias subterrâneas) é marcada por pontos amarelos, a rampa central por traço rosa e a galeria mestre por círculo laranja conforme apresentado na Figura 10b.

As seções de eletrorresistividade apresentaram resistividade elétrica entre 26.4 e 20804 ohm.m. Para a melhor análise e distinção dos resultados definiu-se:

- os valores de resistividade elétrica entre 26.4 e $200 \rightarrow$ baixos resistivos;

- os valores de resistividade elétrica entre 200 a 8000 Ohm.m $\rightarrow$ intermediários e;

- os valores de resistividade elétrica de 8000 a 20804 ohm.m $\rightarrow$ altos.

Perfis ER - Área Sul: (identificados com a cor azul) estão localizados em um baixo topográfico (540 a 560 metros) e ao sul das galerias subterrâneas. As seções elétricas têm como características principais os baixos anômalos (68.5 a 178 ohm.m) nas estações entre 240 e 320 metros de perfil. Na região central das seções (aproximadamente 160 metros) observa-se altos anômalos (8024 a 20804 ohm.m). Nas estações entre 160 e 240 metros de extensão do perfil observa-se o contato entre duas regiões de dipolos que podem estar relacionadas a presença de alguma estrutura geológica como fraturas (Figura 11).

Perfis ER - Galeria mestre: (identificados em vermelho), os perfis 150_M, 160_M e 180_M entre 240 e 320 metros de extensão observa-se baixos anômalos de resistividade elétrica (30 a 170 ohm.m) no topo e na base das seções uma área de contato, com uma resistividade de aproximadamente $15000 \mathrm{ohm} . \mathrm{m}$ variando até $460 \mathrm{ohm} . \mathrm{m}$. A seção 160_M localiza-se acima de uma galeria da mina subterrânea e pode-se correlacionar os dipolos entre 80 e 160 metros de extensão dos perfis às galerias em subsuperfície (Figura 11).

Perfis ER - Zona de Recarga (identificados em amarelo), estão localizados em um alto topográfico (de 595 a 670 metros de altitude). Observa-se entre 160 e 320 metros de extensão a maior concentração de baixos anômalos (de 0 a 200 ohm.m). Em 160 metros de extensão observase um contato entre zonas de altos e baixos anômalos que podem estar associados a presença de estruturas geológicas (Figura 11).

Para melhor diagnóstico e reconhecimento dos limites dos baixos anômalos de resistividade elétrica das seções, foi gerado um modelo de visualização 3D a partir de células com os valores interpolados. Foi definido uma faixa (range) de valores entre 0 a 200 ohm.m. Na Figura 12 foram dispostas imagens dos perfis e as variações resistivas integradas com as galerias subterrâneas da mina em diferentes inclinações e declinações dos eixos $x$, y e z.

$\mathrm{Na}$ Figura $12 \mathrm{a}$ a imagem está com $90^{\circ}$ (graus) de inclinação e $0^{\circ}$ de declinação, observa-se baixos 
anômalos de resistividade elétrica em grande volume na porção SW da área, próximo a rampa central (traço rosa) observa-se a atenuação do volume de baixos resistivos.

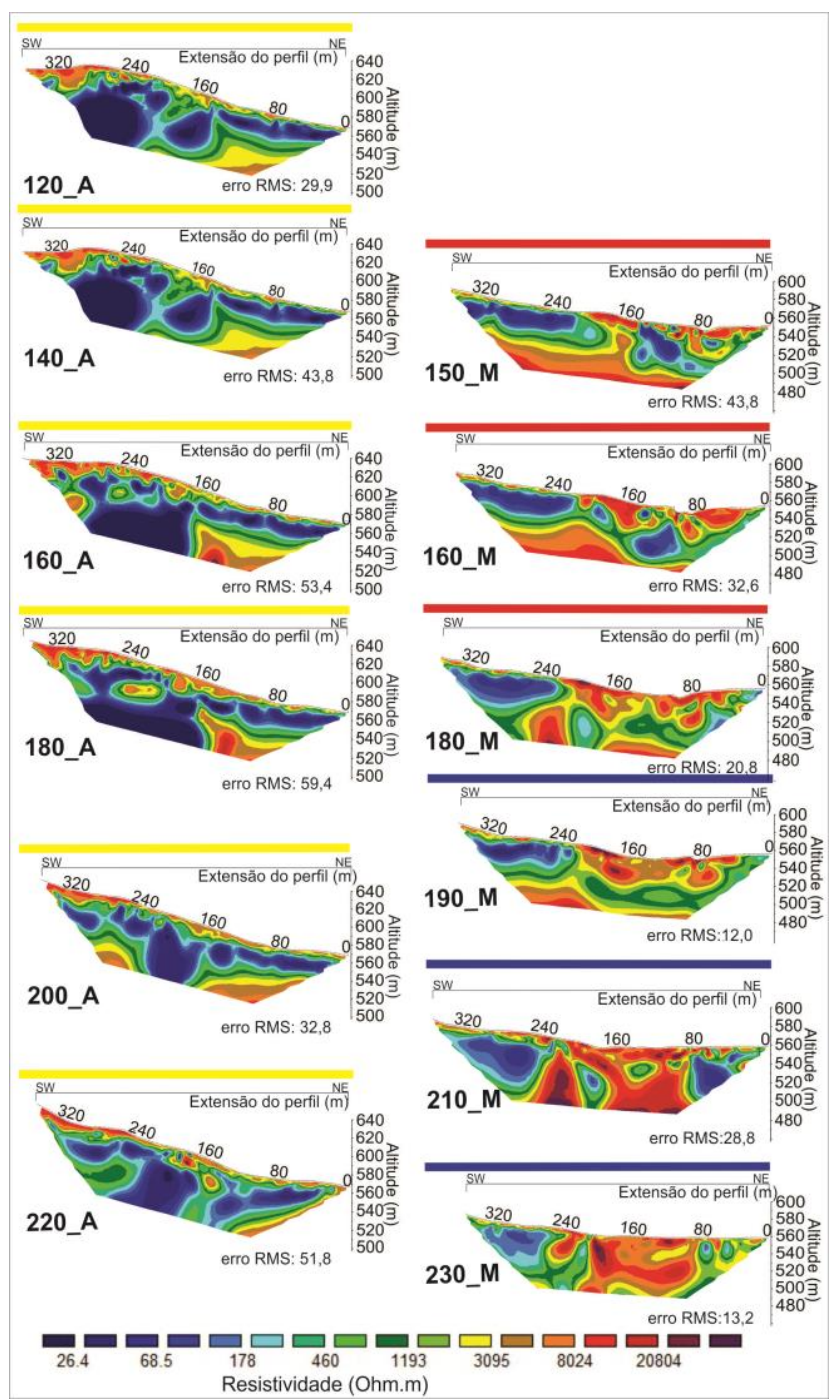

Figura 11 - Seções de eletrorresistividade para cada perfil executado na campanha geofísica.

Na Figura $12 \mathrm{~b}$ com $10^{\circ}$ de inclinação e $109.4^{\circ}$ de declinação com foco na zona de recarga percebe-se que há uma grande concentração de baixos anômalos muito próximas a rampa central. Quando observado com $6^{\circ}$ de inclinação e $-40^{\circ}$ de declinação (Figura 12c) observa-se que a zona de recarga está localizada em um alto topográfico e que a galeria Mestre está localizada próxima a baixos anômalos. A partir da análise em vários ângulos de visualização (Figura 12) das seções de resistividade elétrica conclui-se que há baixos anômalos em um alto topográfico e que as faces de desenvolvimento da mina (esferas amarelas, Figura 10b) localizadas próximo a rampa central e a galeria Mestre estão com tendência de crescimento para a zona de maior concentração dos baixos resistivos.

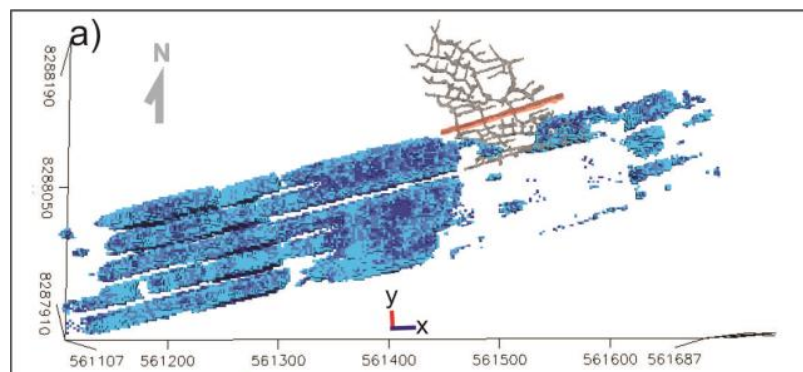

b)

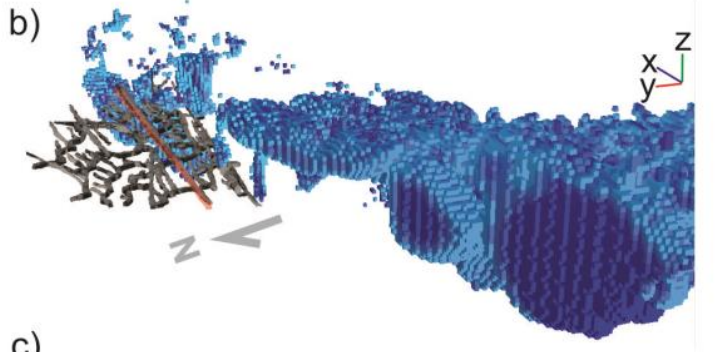

c)

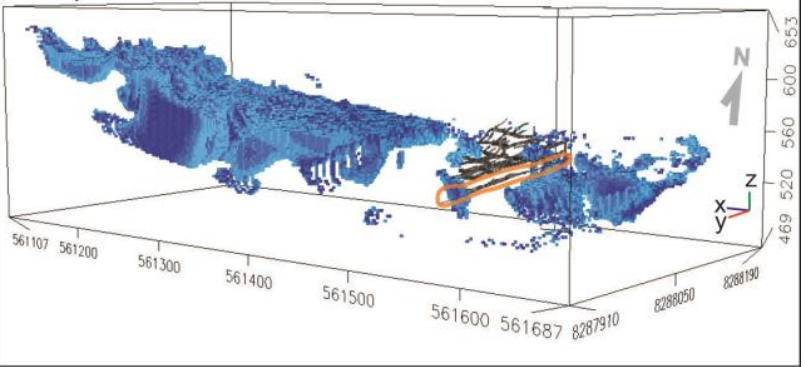

Figura 12 - Em a, b, e c visualização $3 D$ da variação dos valores de resistividade elétrica (entre 0 e 200 ohm.m) nos perfis adquiridos integrados a localização das galerias subterrâneas.

\section{Conclusões}

Os baixos resistivos identificados com 0 processamento e inversão de 12 seções de eletrorresistividade caracterizaram uma zona de recarga localizada em um alto topográfico próximo a faces de desenvolvimento de galerias subterrâneas de uma mina de exploração aurífera em pleno funcionamento.

O uso das informações da localização da zona de recarga, bem como a profundidade de investigação serve de subsídios tanto na delineação e localização de infiltração de água na mina quanto para a decisão de medidas de prevenção para o aproveitamento de forma sustentável dos recursos hídricos da área estudada.

Neste trabalho, a fim de minimizar os custos e otimizar a lavra sugere-se a técnica Drenagem Preventiva de Avanço (DPA), onde faz-se a extração da água por meio de poços de drenagem nas regiões de maior concentração (baixos resistivos, associados ao maior volume de água em subsuperfície).

O método geofísico de eletrorresistividade com o uso da técnica de caminhamento elétrico e do arranjo geométrico polo dipolo mostrou-se eficaz para a caracterização em subsuperfície por meio de contrastes de resistividade elétrica do entorno de uma mina subterrânea. A elaboração deste trabalho visa contribuir 
para estudos posteriores em pesquisas de grande escala para a localização de zonas de recarga com o uso da geofísica aplicada.

\section{Agradecimentos}

Ao Laboratório de Geofísica Aplicada da Universidade Federal do Pampa, campus Caçapava do Sul por todo o suporte em todas as etapas executadas nesse projeto.

A Sociedade Brasileira de Geofísica (SBGf) pelo suporte financeiro por meio de bolsa de iniciação científica.

A Orinoco Gold e Mineração Curral de Pedra LTDA por ceder a área para pesquisas acadêmicas e seus colaboradores no auxílio da execução deste projeto.

\section{Referências}

Almeida, F. F. M., Hasui, Y., Brito Neves, B.B., Fuck, R.R. 1977.Províncias Estruturais Brasileiras. In: VIII SIMPÓSIO DE GEOLOGIA DO NORDESTE. Anais..., Paraná: SBG, p.363-391.

Elis, R. V, Barroso R. M. C, Kiang H. C. 2004. Aplicação de ensaios de resistividade na caracterização do Sistema Aquífero Barreiras / Marituba em Maceió - AL. Revista Brasileira de Geofísica. Disponível em: < http://www.scielo.br> Acesso em: 10 Março. 2016.

Filho, S. V. 1997. Estudos de águas subterrâneas com métodos elétricos na região do semi-árido de Patos - PB. Revista Brasileira de Geofísica. São Paulo, V. 15 n. 2.

Fuck, R. A. 1994. A Faixa Brasília e a Compartimentação Tectônica na Província Tocantins, In: SIMPÓSIO DE GEOLOGIA DO CENTRO-OESTE, 4., 1994, Brasília. Anais ... Brasília: SBG - Núcleo GO/DF, 1994. p. 184-187.

Jost, et. al. 2005. Geologia e Geocronologia do Complexo Uvá, Bloco Arqueano de Goiás. Revista Brasileira de Geociências, 35 (4): 559-572.

Loke, M. H. 2000. Eletrical imaging surveys for environmental and engineering studies: A pratical Guide to 2-D and 3-D surveys.

Lopes, P. D. 2009. Água no séc. XXI: desafios e oportunidades. Periódico do CIEDA e do CIEJD, em parceria com GPE, RCE e o CEIS20. ISSN 1647-6336.

Mineração Curral de Pedra. 2017. Banco de dados cedidos pela equipe de geotecnia da mina Cascavel.

Nazaruddin, D. A., Amiruzan, Z. S., Hussin, H., Jafar, M. T. M. 2017. Integrated geological and multi-electrode resistivity surveys for groundwater investigation in Kampung Rahmat village and its vicinity, Jeli district, Kelantan, Malaysia. Journal of Applied Geophysics. 138 (2017) 23-32.

Oliva et. al. 2006. Utilização do método da eletrorresistividade na caracterização hidrogeológica de área de recarga do Sistema Aquífero Guarani. In: XIV CONGRESSO BRASILEIRO DE ÁGUAS SUBTERRÂNEAS. Anais... Curitiba: Associação Brasileira de águas subterrâneas. Disponível em: <https://aguassubterraneas.abas.org/asubterraneas/article /viewFile/23193/15304>. Acesso em: 27 Março. 2017.

Oliveira, M. A. S. 2011. Aplicabilidade do método geofísico de eletrorresistividade na pesquisa de água subterrânea em rochas cristalinas na região de Conceição do Coité - BA. Salvador: Instituto de Geociências, Universidade da Federal da Bahia. Disponível em: < http://www.twiki.ufba.br/twiki/pub/IGeo/GeolMono20111/m urilo_oliveira_2011.pdf>. Acesso em: 27 Março. 2017.

Orinoco Gold. 2017. Banco de dados e mapas geológicos da porção norte do Greenstone Belt Faina, GO.

Rubio, R. F. 2006. A gestão dos recursos hídricos e a mineração. In: visão internacional. Agência Nacional de Águas. Instituto Brasileiro de Mineração. Brasília: ANA. p. 19-49.

SIEG. Sistema Estadual de Geoinformação. SIG - Banco de dados do Estado de Goiás. 2017. Disponível em: <http://www2.sieg.go.gov.br/post/ver/171319>. Acesso em: 20 Março. 2017. 